\title{
Institucionalización de la cuestión ambiental en el contexto del (neo) extractivismo minero. El rol del estado argentino en el caso minera Alumbrera Ltd.
}

\author{
Institutionalization of the environmental issue in the context of the mining (neo)extractivism. The role of the \\ Argentine State in the Minera Alumbrera Ltd. case \\ Santiago Pablo Petrocelli \\ CONICET - Centro de Investigaciones Hábitat y Municipio, Facultad de Arquitectura, \\ Diseño y Urbanismo, Universidad de Buenos Aires, Argentina \\ santiagopetrocelli@gmail.com
}

\section{Resumen:}

El objetivo de esta investigación es analizar el rol del Estado argentino en la institucionalización de la cuestión ambiental en el marco de la promoción de la minería a cielo abierto, a partir del caso Minera Alumbrera Ltd. en la Provincia de Catamarca. La estrategia metodológica incluye tareas desarrolladas en gabinete -revisión de bibliografía secundaria, legislación, imágenes satelitales y documentación oficial-y otras en trabajo de campo -entrevistas a actores clave y recolección de documentación oficial-. Entre los resultados, se observó que el horizonte político en materia ambiental fue limitar y reparar los daños, más que incidir en la definición del modelo de desarrollo para fomentar o restringir determinados tipos de relaciones socioecológicas. Se identificó que el sistema estatal de control ambiental, inscripto en una integración periférico-dependiente del territorio catamarqueño a la geografía de la economía globalizada, resultó extremadamente laxo.

Palabras ClaVe: Institucionalización Ambiental, Minería a cielo abierto, Rol del estado.

\section{ABstract:}

The objective of this research is to analyze the role of the Argentine State in the institutionalization of the environmental issue within an open-pit mining promotion framework, based on the case of Minera Alumbrera Ltd. in Catamarca Province. The methodological strategy includes indoor tasks — revision of secondary bibliography, legislation, satellite images and official documentation - as well as field work - interviews to key actors and collection of official documentation. Among the results, it was observed that the environmental political horizon was limiting and repairing damages, rather than influencing the definition of a development model in order to promote or restrict certain types of socio-ecological relations. It was identified that the state environmental control system, framed in a periphery-dependent integration of the Catamarca territory to the geography of the globalized economy, was extremely lax.

KEYWORDS: Environmental institutionalization, Open-pit mining, The rol of the state.

\section{INTRODUCCIÓN}

Las actividades humanas suponen un particular entramado de relaciones entre la sociedad y el mundo biofísico y, por ende, la adopción de un modelo de desarrollo ${ }^{1} \mathrm{u}$ otro implica transformaciones en tal contexto (Bustamante, 2007; Colby, 1991). Estas relaciones no importaban demasiado cuando las actividades antrópicas sucedían en una pequeña escala en comparación con la naturaleza (Colby, 1991) y, de modo opuesto, se vuelven centrales desde fines de siglo pasado con el incremento en el tamaño de los proyectos de extracción y comercialización de bienes comunes naturales de la mano de tecnologías no convencionales. Entre estas actividades de fuerte impacto ambiental se encuentra la minería a cielo abierto, la fractura hidráulica para extracción de gas y petróleo y la agricultura industrial transgénica.

Entendiendo al ambiente como resultado de interacciones entre sistemas ecológicos y socioeconómicos, capaces de generar efectos en seres vivos y actividades antrópicas (Brailovsky y Foguelman, 1991), se considera 
que los problemas ambientales emergen de un proceso histórico de selección de riesgos y son socialmente construidos mediante un proceso dialógico. Sin embargo, la crisis ambiental no sólo es producto de estrategias discursivas, intereses políticos y económicos, sino que fundamentalmente deriva de los procesos de la racionabilidad económica occidental y de la revolución industrial desde donde nace la ciencia moderna que divide la realidad en campos disciplinarios confinados (Leff, 2010). Por ello, el análisis ambiental exige un abordaje interdisciplinario, sistemático y holístico (Ferro, 2015).

El aumento de las presiones sobre metales y minerales dispersos en la naturaleza latinoamericana, acaecido desde fines de siglo pasado, ${ }^{2}$ se asocia - en buena medida- a la ascendente dependencia de Estados Unidos y China respecto del abastecimiento extranjero para satisfacer sus crecientes necesidades (Delgado Ramos, 2010); vinculadas al giro capitalista del país asiático y a transformaciones estructurales en el metabolismo social que, de la mano del avance científico-tecnológico, modificaron el carácter estratégico de determinados materiales. Un ejemplo de ello se observa en la industria automotriz, donde el contenido promedio de cobre - principal mineral de extracción de Minera Alumbrera Ltd.- de un automóvil en 1948 fue de 45m, mientras que a principios de este siglo alcanzó 1.600m (National Research Council, 2008).

Para diferenciar al renovado impulso extractivista de las últimas décadas, que tiene sus propias particularidades respecto del extractivismo desplegado junto a la invasión europea sobre sociedades y naturalezas latinoamericanas, Svampa y Viale (2017) utilizan el prefijo neo. El (neo)extractivismo es entendido como un modelo de desarrollo económico y patrón de acumulación basado en la sobreexplotación de bienes comunes naturales y la expansión de las fronteras de explotación sobre territorios antes considerados como improductivos, con un incremento en la envergadura de las inversiones y los actores intervinientes (Svampa y Viale, 2017). Además, desplegado en el marco de un intenso proceso de globalización y financiarización de la economía y de consolidación de grandes empresas transnacionales especializadas en la producción y comercialización de commodities a escala planetaria.

Si bien la globalización económica implicó la propagación de los problemas ambientales por todo el planeta, esto afectó de forma diferencial a las regiones y formaciones sociales en relación a su particular posicionamiento en la división internacional del trabajo, su estrategia de inclusión en la economía global y sus deudas externas (Ferro, 2015). Diversos académicos (Alimonda, Pérez, y Martín, 2017; Delgado Ramos, 2014; Gudynas, 2017; Machado Aráoz, 2015; Svampa y Viale, 2017) acuerdan en que la proliferación de actividades económicas de carácter extractivo-intensivo en América Latina, entre ellas la minería a cielo abierto, se inscribe en un comportamiento sistémico ligado a una particular forma de ordenamiento territorial del sistema capitalista a nivel planetario. Desde esta perspectiva, puede afirmarse que el (neo)extractivismo se configura en una forma de ordenamiento territorial que

ajusta la integración subordinada y dependiente de los territorios periféricos como ensamblajes perfectamente articulados a la dinámica de la geografía económica globalizada, cuya contracara (y cuyo costo) no sólo es el profundo desorden socioterritorial estructural que impera al interior de las "economías nacionales", sino también la creciente incapacidad de la sociedad política local para disponer, controlar, organizar y administrar el propio territorio (Machado Aráoz, 2015, p. 28).

La minería a cielo abierto se funda en la transferencia de activos ecológicos desde formaciones sociales periférico-dependientes hacia otras centrales-dominantes mediante los flujos del comercio exterior. Proceso basado en una jerarquización fundacional del espacio geográfico moderno, que discrimina áreas de sacrificio/ aprovisionamiento y centros de destino/acumulación (Machado Aráoz, 2015). En cuanto a los intereses de los gobiernos de unas áreas y otras, Colby (1991) menciona que a fines de siglo XX los gobiernos de países en desarrollo - naciones periférico-dependientes- usualmente consideraron las preocupaciones ambientales como algo contrario a sus necesidades, y asociado a un interés de la clase elitista de países ricos -centros de destino/acumulación-.

Estos intereses diferenciales se reflejaron en el rol de los Estados de unas y otrasáreas, de modo que al tiempo en que se recrudecían las restricciones ambientales para el despliegue de la minería a cielo abierto en países 
centrales, gobiernos latinoamericanos incentivaban la transferencia de minerales mediante otorgamiento de facilidades y privilegios económicos al capital minero extranjero, flexibilización de regulaciones ambientales e irrestricto acceso al uso masivo de agua dulce que demanda el proceso productivo (Delgado Ramos, 2010).

Los emprendimientos de minería a cielo abierto suelen promocionarse bajo discursos asociados al desarrollo, progreso, creación de empleo y cuidado ambiental. El poder corporativo minero realiza notables esfuerzos por encubrir los perjuicios ambientales de la actividad y asociarla a una narrativa del desarrollo sustentable. ${ }^{3}$ Sin embargo, la combinación de la creciente lista de casos de contaminación, el activismo de movimientos socioambientales en contra de la minería a cielo abierto y el trabajo de sectores académicos críticos del (neo)extractivismo minero, ha contribuido a quitar el velo de sus sensibles implicancias ambientales y socavado su legitimidad.

De cara al cuadro de situación mencionado, la administración ambiental y su vínculo con el desarrollo económico se ha vuelto un tema de notable relevancia. Así como también se considera de creciente interés realizar un esfuerzo para deconstruir las formas de relacionamiento socioecológicas que promueven las instancias estatales de regulación y gestión ambiental en el marco de las políticas de desarrollo. De modo que el Estado es un actor clave por su capacidad de establecer nuevos órdenes normativos que modelen el tipo de relación predominante entre sistemas socioeconómicos y ecológicos.

En base a lo expuesto, el objetivo de este trabajo es analizar el rol del Estado argentino -en sus distintos niveles- en la institucionalización de la cuestión ambiental en el marco de la promoción de la minería a cielo abierto. Esto, a partir del caso Minera Alumbrera Ltd. en la Provincia de Catamarca y de sus particulares implicancias ambientales. Para ello, la estrategia metodológica incluye tareas que se desarrollaron (i) en gabinete con revisión de bibliografía secundaria, marcos legislativos, imágenes satelitales y consulta de documentación oficial de Minera Alumbrera Ltd. (ii) y otras en trabajo de campo en la capital de la Provincia de Catamarca y tres localidades próximas a la mina, ${ }^{4}$ donde se realizaron entrevistas a actores clave y se recolectó documentación oficial.

En lo que sigue, el artículo se estructura en tres apartados. Primero, se presentan las principales implicancias ambientales de la minería a cielo abierto, a partir del despliegue territorial de Minera Alumbrera Ltd. Luego, se analiza el rol del Estado Nacional y de la Provincia de Catamarca en la institucionalización de la cuestión ambiental frente al avance de la actividad en el territorio, lo que incluye sanción de nueva legislación y conformación de áreas de gobierno para su aplicación. Finalmente, se realizan una serie de conclusiones y consideraciones finales respecto de la regulación y gestión ambiental aplicada por el Estado argentino en el contexto de la inserción y avance del (neo)extractivismo minero en el país.

\section{IMPLICANCIAS AMBIENTALES DE MINERA ALUMBRERA LTD. EN EL TERRITORIO}

A diferencia de la minería tradicional de explotación en vetas, que se aplica en sitios con alta concentración relativa de minerales, la tecnología para la minería a tajo abierto fue diseñada a fines de siglo pasado para extraer el remanente de pequeñas partículas de mineral diseminadas en grandes extensiones de roca. Para ello, se procede a la voladura de miles de hectáreas de montaña para capturar el material rocoso, triturarlo y someterlo a procesos de lixiviación en pilas, con grandes cuantías de agua dulce combinadas con ácido sulfúrico, mercurio y/o cianuro, según el tipo de mineral a separar (Machado Aráoz, 2009b; Svampa, Bottaro, y Sola Álvarez, 2009).

La utilización de esta tecnología tiene serias implicancias ambientales a corto, mediano y largo plazo. Utiliza millones de litros de agua dulce por día para el proceso productivo en sitios semiáridos y desecha un drenaje ácido que suele afectar de manera irreversible cursos y fuentes de agua. El consumo de energía es intensivo y, además, el costo ambiental de su producción -generalmente invisibilizado- lo internalizan los países mineros. Toneladas de explosivos peligrosos - ANFO- son transportadas por rutas que atraviesan distintos poblados hasta llegar a ser utilizados en la mina. Los gases nitrosos liberados como consecuencia 
de las voladuras producen lluvias ácidas, acarreando efectos nocivos en flora y fauna (Delgado Ramos, 2010; Machado Aráoz, 2009a; Rodríguez Pardo, 2009). Respecto de esto último, en ocasión de trabajo de campo en Hualfín, localidad ubicada a $24 \mathrm{~km}$ del tajo abierto de Minera Alumbrera Ltd., empleados municipales señalaron haber visto zorros pelados por la zona.

Minera Alumbrera Ltd. (MAA) fue el primer emprendimiento de minería a cielo abierto en Argentina, instalado bajo promesas de despegue económico y productivo en una provincia con graves niveles de pobreza estructural y desempleo crónico. A comienzos de la década de 1990, en connivencia con un Estado Nacional y provincial anfitrión de los capitales transnacionales, el sector corporativo minero logró acomodar el marco regulatorio de la actividad a sus intereses. En 1994, MAA comenzó la construcción y gestión de la mina, equipamientos, servicios e infraestructuras para la explotación, logística y comercialización del producto. Una vez acondicionado el territorio, en 1997 comenzó la extracción de minerales, principalmente cobre, oro y molibdeno. El promedio de producción anual declarado por la empresa ronda 100.000 toneladas de cobre, 300.000 onzas troy de oro, 33.000 onzas de oro doré y 1.900 toneladas de concentrado de molibdeno (Minera Alumbrera Ltd., 2017).

MAA resolvió el abastecimiento de explosivos, maquinarias, vehículos, químicos, bolas de acero para la molienda y piezas de metalurgia a través de empresas transnacionales especializadas en prestar servicios a la minería de gran escala. Por otro lado, se abastece de gasoil desde Buenos Aires, de energía desde Tucumán y de agua en Catamarca. MAA consiguió un permiso del Gobierno de Catamarca para extraer 1.200 litros de agua por segundo -aproximadamente 100 millones de litros de agua dulce al día- y utiliza un equivalente al 170 \% de la energía que consume toda la Provincia de Catamarca, a través de una línea de alta tensión privada que llega desde Tucumán para abastecer al proyecto. Además, sólo para el funcionamiento de sus flotas de grandes camiones y excavadoras consume más de 33 millones de litros de combustible diésel por año (Machado Aráoz, 2009b).

Si bien la mina se encuentra en Catamarca, el despliegue territorial del emprendimiento comprende instalaciones, flujos e impactos en varias provincias argentinas. En Catamarca, con el empleo de poderosos explosivos -ANFO- y camiones que cargan hasta 240 toneladas, se separa la roca del macizo montañoso. En partes aproximadamente iguales, el volumen desprendido se divide entre (i) aquel que por su bajo contenido de minerales no se somete a ningún tratamiento y pasa a conformar el depósito de estériles, estimado en 700 hectáreas, y (ii) aquél que continúa el circuito productivo y se tritura para separar el mineral de la roca en la Planta Concentradora, con la utilización de químicos y grandes cuantías de agua dulce. De allí se obtiene el concentrado de cobre y oro, que representa el 0,30\% de todo el material ingresado a la Planta Concentradora. El material restante es enviado al dique de cola, cuya superficie se estima en 900 hectáreas. ${ }^{5}$

El mencionado depósito de estériles y el dique de cola, así como el tajo abierto en el macizo montañoso, quedarán en el paisaje catamarqueño una vez que MAA termine la explotación, dejando un incremento de la superficie expuesta de minerales y químicos que se encontraban retenidos en matrices rocosas y residuos químicos como cianuro, cloratos y arsénico, entre otros contaminantes utilizados en el proceso de lixiviación, retenidos en el dique de cola. Al respecto, cabe señalarse que el riesgo de filtración de estos contaminantes es permanente y agravado por las condiciones sísmicas de la zona.

El concentrado, mineral en forma de barro fluido, es transportado mediante un mineraloducto de 170 mm de diámetro hasta una Planta de Filtros localizada en Tucumán, a $316 \mathrm{~km}$ de la Planta Concentradora. Allí, se extrae el agua del concentrado, que la empresa desecha -sin tratamiento hasta 2001- en un efluente local. Luego, los minerales sólidos se transportan en convoyes ferroviarios hasta el interior del puerto que MAA administra al norte del Área Metropolitana de Rosario, en los márgenes del Río Paraná -en un sector cuyo calado habilita el acceso de buques de ultramar desde y hacia el Océano Atlántico-, para el despacho del producto a mercados internacionales.

Entre los impactos ambientales más relevantes de MAA, se incluyen afectaciones en la calidad del agua de las cuencas hídricas Vis Vis-Amanao -Catamarca- y Salí Dulce - Tucumán, Santiago del Estero y Córdoba-. 
Además, en Catamarca se extraen grandes volúmenes de agua de un reservorio cuya capacidad de recarga no se encuentra asegurada. El riesgo de contaminación accidental en los $316 \mathrm{~km}$ de extensión del mineraloducto, que ya ha registrado roturas y fugas en distintos sectores, es una constante. En el sitio de extracción se produce una profunda alteración geomorfológica y del paisaje, una destrucción irreversible de ambientes nativos, un depósito de residuos peligrosos permanentes, derrames accidentales de sustancias peligrosas y contaminación del aire por la voladura con explosivos ANFO.

En el año 2003, un exinspector de Calidad Minera de la Provincia de Catamarca demostró filtraciones en el dique de colas que contaminaron la cuenca del Río Vis Vis (Nieva, 2002). Al año siguiente, habitantes del pueblo Vis Vis - ubicado a sólo $3 \mathrm{~km}$ del dique de cola- realizaron una denuncia civil contra la empresa por daños de contaminación y destrucción de sembradíos y ganado, teniendo que relocalizarse en otra localidad. En relación a ello, funcionarios municipales de Andalgalá, localidad ubicada $25 \mathrm{~km}$ al este del mencionado pueblo, mencionaron la afluencia de familias asentadas en áreas rurales próximas a la mina y la desaparición del pueblo Vis Vis. ${ }^{6}$ En 2004, se produjo el primer derrame de concentrado reconocido públicamente por MAA. En 2006 y 2007, también se registraron fugas en el mineraloducto, en Catamarca y en Tucumán respectivamente. En 2008, habitantes de Tinogasta realizaron cortes de ruta para denunciar daños en sus viviendas y calles debido al tránsito de los vehículos de gran porte de la empresa (Rodríguez Pardo, 2011).

Si bien la Provincia de Tucumán no alberga proyectos de minería a cielo abierto, su geografía es receptora en tránsito del material extraído y depósito del agua de fluidización del barro mineral. Se trata de residuos líquidos que contienen metales pesados y la empresa vierte al canal de desagüe rural DP2, cuyo cuerpo receptor es el embalse Río Hondo que Tucumán comparte con Santiago del Estero. Recién en 2001, cuatro años luego del comienzo de la actividad y debido a muestreos judiciales que detectaron presencia de metales pesados por encima de los valores admitidos, MAA instaló un sistema de tratamiento de efluentes previo al volcado. Pese a ello, los impactos de la actividad en Planta de Filtros continuaron siendo objeto de numerosas denuncias de organizaciones ambientalistas (Adler, 2014).

\section{El ROL DEL ESTADo EN LA INSTITUCIONALIZACión DE LA CUESTIÓN AMBIENTAL}

A los fines de plantear una base conceptual que oriente el análisis del sistema de valores, creencias y acciones que subyace en el proceso de institucionalización ambiental llevado a cabo por el Estado nacional y provincial de cara al avance de la minería a cielo abierto, se presentan los paradigmas de la administración ambiental del desarrollo trabajados por Colby (1991), retomados por Bustamante (2007), Martínez Idrobo y Figueroa Casas (2014) - los cuales se articulan bajo disímiles supuestos respecto de la naturaleza humana, la propia naturaleza, el desarrollo económico y sus mutuas interacciones- y el emergente campo epistémico de la Ecología Política. Se trata de enfoques que son objeto de debate, disputa y reformulación en el ámbito académico y político, a continuación presentados de manera sucinta (Tabla 1). 
TABLA 1 (A)

Enfoques relativos a la gestión de la relación entre sistemas socioeconómicos y ecológicos

\begin{tabular}{|c|c|}
\hline $\begin{array}{c}\text { Enfo- } \\
\text { que }\end{array}$ & Descripción \\
\hline 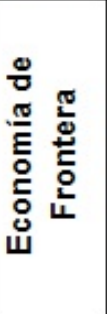 & $\begin{array}{l}\text { Bajo esta noción, la gestión ambiental se orienta a abastecer demandas de sectores } \\
\text { industriales y productivos considerando a la naturaleza como fuente infinita de recursos } \\
\text { físicos pasibles de ser transferidos a la economía y, a la vez, resumidero infinito de los } \\
\text { desechos de la sociedad. Subyace un pensamiento positivista de optimismo respecto del } \\
\text { avance tecnológico, donde la naturaleza resulta manipulable e incluso reemplazable. Bajo } \\
\text { este enfoque, las tecnologías se orientan a aumentar el poder del hombre en la extracción } \\
\text { de recursos y producción de la naturaleza (Bustamante, 2007; Colby, 1991; Martínez ldrobo } \\
\text { y Figueroa Casas, 2014). }\end{array}$ \\
\hline 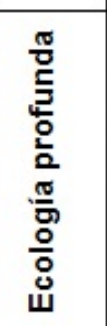 & $\begin{array}{l}\text { Surge como reacción y antítesis de la Economía de frontera, de modo que promueve una } \\
\text { gestión ambiental basada en la igualdad intrínseca de las bioespecies, autonomía } \\
\text { biorregional -no dependencia tecnológica, económica y cultural-, planificación } \\
\text { descentralizada, economías no basadas en el crecimiento, control de la natalidad, mínima } \\
\text { intervención sobre la naturaleza y utilización de sistemas locales de tecnología y } \\
\text { administración. Retoma tradiciones filosóficas que promueven una relación armoniosa entre } \\
\text { naturaleza y humanidad basadas en principios éticos, sociales y morales subestimados en el } \\
\text { pensamiento hegemónico (Bustamante, 2007; Colby, 1991). }\end{array}$ \\
\hline 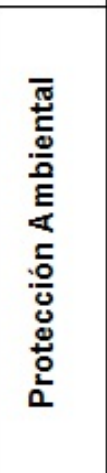 & $\begin{array}{l}\text { Es una versión moderada de la Economía de frontera, de modo que busca limitar y reparar } \\
\text { los daños sin incidir en la planificación del desarrollo o el metabolismo social. Se preocupa } \\
\text { especialmente por los efectos de la contaminación en la salud y en las especies } \\
\text { amenazadas. Esta noción permeó en las estructuras institucionales de varios Estados } \\
\text { industrializados a partir de la década de } 1970 \text {, en los que se crearon áreas gubernamentales } \\
\text { de "Protección Ambiental" }{ }^{7} \text { así como instrumentos legales, normativos y técnicos }{ }^{8} \text { dirigidos a } \\
\text { establecer relaciones aceptables -o no- del tipo costo-beneficio de la contaminación } \\
\text { ambiental en función del desarrollo económico y social. Bajo esta perspectiva, la gestión } \\
\text { ambiental se basa en la legalización del ambiente como exterioridad económica con una } \\
\text { actitud correctiva-defensiva, incluyendo la prescripción de nuevas soluciones tecnológicas } \\
\text { para mitigar impactos negativos, considerados como un incremento en el costo de la } \\
\text { actividad productiva (Bustamante, 2007; Colby, 1991). }\end{array}$ \\
\hline 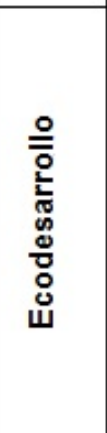 & $\begin{array}{l}\text { Plantea una superación de la dicotomía entre el ecocentrismo de la Ecología profunda y el } \\
\text { antropocentrismo de la Economía de frontera. Propone una reorganización de las } \\
\text { actividades antrópicas para que sean sinérgicas con los servicios y procesos de los } \\
\text { ecosistemas y un crecimiento a escala biofísica, manteniendo un nivel de consumo per } \\
\text { cápita sostenible mientras se logra el crecimiento del bienestar económico. Incorpora la } \\
\text { precaución e incertidumbre ecológica en la planificación económica, lo que requiere } \\
\text { actuaciones de largo plazo, y postula que la prevención de la polución es rentable. Su } \\
\text { implementación exige estructuras de participación en la planificación y gestión de los } \\
\text { modelos de desarrollo. Entre sus instrumentos, promueve elevar impuestos a actividades } \\
\text { extractivas y fuertemente contaminantes y disminuirlos para aquellas que no lo son (Colby, } \\
\text { 1991; Bustamante, 2007). }\end{array}$ \\
\hline
\end{tabular}


TABLA 1 (B)

Enfoques relativos a la gestión de la relación entre sistemas socioeconómicos y ecológicos

\begin{tabular}{|c|c|}
\hline 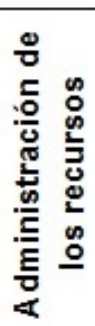 & $\begin{array}{l}\text { asocia a la idea básica de incluir todos los tipos de capital y recursos -monetarios, } \\
\text { raestructurales, humanos y biofísicos- en las políticas de desarrollo y planificación de la } \\
\text { /ersión. Si bien el cuidado ambiental aparece como una condición necesaria, el } \\
\text { ecimiento económico continúa siendo la meta principal de la noción de desarrollo que le } \\
\text { byace a este modelo; que se apoya en las nuevas tecnologías para aumentar la eficiencia } \\
\text { ergética y el cuidado ambiental, y en el principio de la interiorización de los costos sociales } \\
\text { la polución, en otras palabras, en el principio de que el contaminador paga (Colby, 1991; } \\
\text { Istamante, 2007). }\end{array}$ \\
\hline 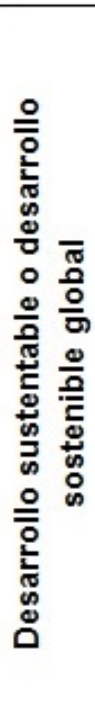 & $\begin{array}{l}\text { Es una instancia posterior del paradigma de la Administración de los recursos y el más } \\
\text { ambiguo de los presentados en este cuadro, dada la diversidad de enfoques -muchas veces } \\
\text { contradictorios- sobre la noción de desarrollo que se le imputan. Articula conceptualmente al } \\
\text { desarrollo económico, social y ecológico en una misma unidad sistémica. Según Bustamante } \\
\text { (2007) y Jiménez Herrero (1997), sus principios rectores son la equidad y solidaridad a } \\
\text { niveles internacionales e intergeneracionales, forman parte de este paradigma la atención a } \\
\text { las causas de la contaminación antes que a sus efectos, la toma de decisiones mediante } \\
\text { consulta pública, a las ONG y a la comunidad científica, y el reordenamiento de sistemas } \\
\text { jurídicos para la previsión y solución de disputas ambientales nacionales e internacionales. } \\
\text { Por su lado, Swyngedouw (2011) denuncia que la noción de planificación sostenible oculta } \\
\text { un discurso profundamente reaccionario y conservador, en tanto promueve "una serie de } \\
\text { dispositivos técnico-directivos, a menudo caracterizados como radicales o innovadores, que } \\
\text { deben asegurar que la 'civilización' tal y como la conocemos pueda continuar (...) se llama a } \\
\text { una revolución sin cambio revolucionario." (p. 52). El autor señala que su funcionamiento se } \\
\text { basa en el consenso sobre lo dado y la representación ontológica de la naturaleza, } \\
\text { eclipsando el momento político de otorgarle sentido y colocando al ordenamiento } \\
\text { socioecológico en el marco de una dirección técnica y gerencial, fuera de la profunda disputa } \\
\text { política que le subyace. }\end{array}$ \\
\hline 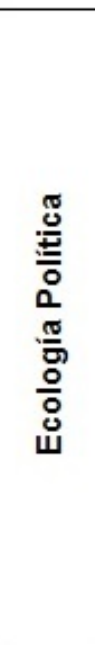 & $\begin{array}{l}\text { Mientras que el paradigma del Desarrollo sustentable plantea cambios de tipo reformistas, la } \\
\text { Ecología Política pone en jaque la concepción hegemónica del desarrollo y plantea un } \\
\text { cambio radical del sistema como única vía de solución al problema ambiental. Su } \\
\text { perspectiva analítica no sólo se refiere a las políticas ambientales, a su formulación e } \\
\text { implementación, sino que abarca al conjunto de las políticas -públicas y privadas- porque } \\
\text { entiende que todas ellas tienen implicancias ambientales. Este enfoque postula que las } \\
\text { interacciones entre humanidad y naturaleza son constituidas y mediatizadas por relaciones } \\
\text { políticas de poder, volviéndose central el análisis de los procesos de significación, } \\
\text { valorización y apropiación desigual de la naturaleza. En el marco de las asimétricas } \\
\text { relaciones históricamente configuradas entre territorios y grupos humanos, la distribución de } \\
\text { costos y beneficios del uso ecológico, así como las estrategias de apropiación de bienes } \\
\text { comunes y servicios ambientales devienen en elementos clave de este campo teórico- } \\
\text { práctico actualmente en construcción; donde confluyen disciplinas como la economía } \\
\text { ecológica, la sociología política, el derecho ambiental, la ética política y la antropología de } \\
\text { las relaciones cultura-naturaleza (Alimonda , 2017; Delgado Ramos, 2010; Leff, 2003; } \\
\text { Machado Aráoz, 2015). }\end{array}$ \\
\hline
\end{tabular}

Fuente: Elaboración propia

En cuanto al rol del Estado en la institucionalización de la cuestión ambiental, se entiende que, en relación a su posibilidad de establecer nuevos marcos regulatorios y formas de articulación entre actores y dependencias estatales con disímiles competencias y capacidades de gestión, actúa - por acción u omisión- como árbitro en el entramado de actores e intereses que interpelan la configuración, uso y usufructo del ambiente. El 
Estado argentino es federal y, como tal, presenta distintos ámbitos y escalas de gestión pública, con funciones exclusivas, concurrentes y complementarias. De mayor a menor nivel de cobertura territorial, primero se presenta el Estado Nacional, luego los Estados provinciales y, bajo su órbita, los gobiernos locales. En relación a esta fragmentación institucional del territorio, se acuerda con Blanco (2007) en que no se debe considerar al Estado como un actor monolítico, de modo que no es ajeno a contradicciones, intereses contrapuestos y capacidades de intervención divergentes en cada uno de sus niveles y dependencias.

La actividad minera cuenta con un código propio, el Código de Minería establecido en el año 1886. El mismo rige sobre los derechos, obligaciones y procedimientos sobre la adquisición, explotación y aprovechamiento de minerales (Art. 1). Reconoce el dominio estatal de los recursos mineros y a la vez prohíbe al Estado explotar en forma directa las minas (Art. 9), siendo su deber conceder la actividad empresarial a particulares para su explotación mediante la concesión legal, y vigilar el cumplimiento de la Ley en cuanto a distribución y explotación de recursos mineros (Catalano, 1999).

La minería a cielo abierto penetró en Argentina en la década de 1990, en un contexto de reformas neoliberales que fundaron un nuevo marco jurídico-político, bajo argumentos asociados a la necesidad de reunir un perfil atractivo para los inversores. En este período sucedieron dos procesos que marcaron los modos de articulación entre los distintos estamentos del Estado y la actividad minera. Por un lado, en línea con el Consenso de Washington, se impulsaron procesos de descentralización administrativa y financiera hacia niveles subnacionales y, por el otro, en el contexto del aumento del precio y demanda de commodities, se han incrementado las inversiones extranjeras directas para extracción y exportación de minerales.

La Provincia de Catamarca, periférica respecto de los principales nodos de producción y consumo del país, en su legislación proclama el deber del Estado Provincial de fomentar la extracción mineral. En 1983, se modificó el Régimen de Inversión Minera (Decreto Ley 4.007), y se declaró de interés provincial el desarrollo permanente y autosostenido de las actividades mineras y el objetivo de contribuir al desarrollo de la Provincia a partir del aumento de la producción mineral, así como de satisfacer las normas vigentes sobre contaminación ambiental, salubridad, higiene y seguridad industrial. La Constitución de la Provincia (1988) indica que el gobierno obligatoriamente promoverá la extracción de minerales (Art. 67). Asimismo, plantea garantizar la iniciativa privada y fomentar actividades productivas, entre ellas la minera, con créditos, exenciones impositivas, adjudicación de tierras fiscales y subsidios en tarifas públicas (Art. 55).

En 1993, desde el ámbito nacional se desplegó una batería de normativas para incentivar la actividad. Entre ellas, La Ley Nacional Inversiones Mineras (Ley 24.196/1993), a la cual Catamarca adhirió (Ley 4.759/93) ese mismo año, fija beneficios económicos e impositivos ${ }^{9}$ a los inversores mineros y establece que las empresas deben constituir una previsión especial para subsanar efectos negativos que pudieran generarse por el desarrollo de la actividad, cuyo importe queda a criterio de la empresa y deducible en la determinación del impuesto a las ganancias. Más allá de las laxas condiciones de esta previsión, subyace en el Estado un reconocimiento de la posibilidad de contaminación.

Por su lado, el Acuerdo Federal Minero (Ley 24.228/1993), al cual Catamarca adhiere en 2001 (Ley 5.046), confiere a las provincias la potestad de transferir a la actividad privada los procesos de exploración y explotación minera, eximiendo a las empresas del pago de impuestos nacionales y obligando a las provincias a eliminar gravámenes y tasas municipales que afecten directamente a la actividad. Incluso, obliga al Estado Nacional y a las Provincias a tomar "las medidas necesarias para evitar distorsiones en las tarifas de energía eléctrica, gas, combustibles y transporte que pudieran afectar a la actividad minera.” (Ley 24.228/1993)

En 1994, la Reforma Constitucional incorporó el derecho ambiental ${ }^{10}$ al marco legal argentino con el Art. 41 y consagró el dominio originario de las provincias sobre los recursos naturales existentes en su territorio con el Art. 124, reservando a la Nación el derecho de establecer lineamientos de mínima sobre su gestión y fijando en la esfera subnacional la potestad de resolver conflictos vinculados al manejo de recursos naturales. A diferencia de la $\mathrm{CN}$, la catamarqueña no establece el derecho ambiental de su población, al respecto solo 
se indica que le corresponde al Poder Legislativo "elaborar normas protectoras del medio ambiente, sistema ecológico y patrimonio natural (...)” (Art. 110). El mencionado Art. 41 de la CN indica:

Todos los habitantes gozan del derecho a un ambiente sano, equilibrado, apto para el desarrollo humano y para que las actividades productivas satisfagan las necesidades presentes sin comprometer las de las generaciones futuras (...). El daño ambiental generará prioritariamente la obligación de recomponer (...). Las autoridades proveerán a la protección de este derecho, a la utilización racional de los recursos naturales, a la preservación del patrimonio natural y cultural y de la diversidad biológica, y a la información y educación ambientales. (...) (Art. 41 CN 1994).

A continuación, haremos algunas consideraciones al respecto. En primer lugar, el derecho ambiental se instaló en la CN como un derecho individual, que a diferencia del derecho a la propiedad incide sobre toda la comunidad, sobre todos los habitantes. Se incorporó la figura de daño ambiental, que procura la indemnización de un daño para un patrimonio colectivo. En ello, se adhiere al principio de que el contaminador paga, con la posibilidad de traducir daño ambiental en costo económico. En el objetivo transgeneracional, subyace la noción de la naturaleza como bien escaso y en peligro, se la reconoce como un bien colectivo que precisa de la delimitación de los derechos individuales (Ferro, 2015). Por su lado, la noción de ambiente es fuertemente antropocéntrica en tanto hace referencia a un ambiente sano, ${ }^{11}$ apto para el desarrollo humano y las actividades productivas.

Por otro lado, el derecho humano al agua -bien común e insumo altamente demandado por la minería a cielo abierto- no forma parte de la CN. El agua sólo es incluida en el Art. 124 como recurso natural bajo el dominio originario de las provincias. Por omisión, la disputa sobre la consideración del agua como mercancía o como derecho humano se resuelve a favor de la primera posición. Como ejemplo empírico, los habitantes de la cabecera departamental ubicada aguas abajo de Minera Alumbrera Ltd. no participan de la gobernanza del agua. Si así fuera, en el ejercicio de sus derechos políticos, los habitantes de Andalgalá se inscribirían dentro de la discusión sobre los valores y principios que deberían orientar la gestión del agua, la asignación de sus servicios, su relación con los ecosistemas, las instituciones y autoridades que deberían intervenir, entre otros aspectos básicos (Ferro, 2015).

A nivel nacional, en 1995, se establecieron los instrumentos de gestión ambiental para la actividad con la sanción de la Ley Ambiental Minera de Protección Ambiental (Ley 24.585/1995). Se exigió la presentación de un Informe de Impacto Ambiental (IIA) por parte de los responsables (Art. 6), a ser evaluado por la autoridad de aplicación, que será aquella que las provincias determinen en el ámbito de su jurisdicción (Art. 5), y aprobado mediante una Declaración Jurada de Impacto Ambiental (DJIA) para cada una de las etapas del proyecto o de implementación efectiva (Art. 7), que deberá ser actualizada como máximo en forma bianual (Art. 11). En el mismo año, la Ley de Actualización Minera (Ley 24.498/1995) modificó el Código de Minería y dictaminó que los agentes mineros deben presentar un plan de restauración del espacio natural afectado por los residuos minerales y a neutralizar, conservar o preservar la zona de explotación (Art.4). $\mathrm{Al}$ respecto, en ocasión de trabajo de campo, se relevó que gobiernos locales próximos al emprendimiento Minera Alumbrera Ltd. -Belén, Hualfín y Andalgalá- no tenían conocimiento del plan de cierre de mina.

Si bien desde el ámbito nacional se promovió una descentralización de la gestión del problema ambiental hacia las provincias instadas a aplicar la legislación, esta no fue acompañada de estrategias de fortalecimiento institucional, recursos o acciones tendientes a fortalecer sus capacidades de gestión ambiental. Pese a que el ambiente no reconoce límites jurisdiccionales, tampoco se promovió una gestión interprovincial que atendiera dicha fragmentación institucional. De este modo, la legislación ambiental y su aplicación resultó orientada a la administración de recursos naturales circunscriptos a unidades espaciales aisladas.

En Catamarca, cuando MAA inició la extracción de minerales, la Autoridad de Aplicación Provincial de la Ley Ambiental Minera de Protección Ambiental y del Código de Minería obtuvo el rango de Dirección y dependía del Ministerio de Producción. En 2005 recién se elevó a un rango ministerial como Secretaria de Estado de Minería (SEM). La SEM es el área que recibe el IIA que realiza la empresa minera, lo evalúa y en función de ello otorga (o no) la DJIA que habilita (o no) el inicio de las actividades. Es la autoridad 
provincial competente para realizar monitoreos periódicos para verificar el cumplimiento de las condiciones y obligaciones ambientales exigibles. Según el Juez de Minas, ${ }^{12}$ tiene la función de la política minera, particularmente de atraer capitales. Cuenta con la Subsecretaria de Minería y tres Direcciones, entre ellas -de nuestro particular interés- la Dirección Provincial de Gestión Ambiental Minera (DiPGAM), que cuenta con Departamento de Evaluación de Proyectos, de Geoquímica Ambiental y de Evaluación de Programas Especiales para monitoreos ambientales y coordinación de las evaluaciones de impacto. ${ }^{13}$

En relación a las capacidades de gestión del área gubernamental encargada de la aplicación de la legislación ambiental, resulta llamativo que al año 2011 la DiPGAM contaba sólo con dos personas. Recién en 2012 comenzó su plena actividad, se incrementó el plantel a 12 personas, se direccionaron mayores recursos para el control y gestión ambiental de la actividad. Se destinó el 60 \% de la inversión del área a controles hídricos, aún cuestionados desde el ámbito académico de la Universidad Nacional de Catamarca, ${ }^{14}$ y se designó una directora del área con formación de Ingeniería en Minas, aspecto informal que marca cierta subordinación del ambiente a la minería en el ámbito provincial. Para fines del 2015, la DiPGAM continuó creciendo, contaba con 40 personas a su cargo y Centros de Control Minero Ambiental -oficinas descentralizadas- en las cabeceras departamentales de los cinco municipios mineros: Andalgalá, Belén, Santa María, Tinogasta y Antofagasta de la Sierra. Sin embargo, la vinculación entre estos y los gobiernos locales no fue formalizada. 15 El Centro de Control Minero Ambiental ubicado en Belén no tiene vinculación con la Dirección de Medio Ambiente del Municipio. La información sobre controles e informes de impacto ambiental minero pueden ser consultados individualmente por cualquier persona interesada, pero no se pueden retirar copias del establecimiento ni se realizan audiencias públicas para presentarlos en sociedad. ${ }^{16}$

En cumplimiento del Art. 41 de la CN, que establece el deber de la Nación de dictar las normas que contengan los presupuestos mínimos de protección ambiental, en 2002 el Congreso sancionó la Ley General del Ambiente (Ley 25.675/2002) postulando principios rectores para las políticas ambientales y objetivos de la política ambiental nacional. Entre estos últimos, resultan ausentes consideraciones sobre el desaliento de actividades económicas contaminantes, la promoción de actividades que promuevan relaciones socioecológicas más favorables y la distribución de costos y beneficios del uso ecológico. Por su lado, los principios rectores colocan a las políticas ambientales escindidas de las definiciones del modelo de desarrollo, más bien posicionan al ambiente como recurso para el desarrollo. ${ }^{17}$

$\mathrm{Al}$ respecto, cabe decir que se trata de una Ley marco que fija umbrales mínimos de protección ambiental para las subsiguientes leyes provinciales, sin obligar ninguna acción por parte de los gobiernos provinciales. En el caso de Catamarca, la Provincia no ha elaborado un marco de regulación ambiental acorde a estos umbrales, incluso la Ley de Aguas (Ley 2.577/73) es previa a la irrupción de las fuertes demandas que imprime la minería a cielo abierto sobre el agua de su geografía semidesértica.

En 2010, el Congreso Nacional sancionó el Régimen de Presupuestos Mínimos para la Preservación de los Glaciares y el Ambiente Periglacial (Ley 26.639), en el marco de un intenso debate público marcado por nuevas demandas sociales de protección ambiental y presiones del lobby minero (Álvarez, 2013; Gutiérrez y Isuani, 2013). Esta Ley tiene por objeto preservar los glaciares como reservas estratégicas de agua dulce y, como herramienta fundamental para su implementación, instó a la realización del Inventario Nacional de Glaciares para individualizar, caracterizar y monitorear todos los glaciares y geoformas periglaciares, con actualización cada cinco años como máximo (Art.3, Art. 4). Las implicancias de esta normativa en la minería a cielo abierto son concretas, en tanto prohíbe la exploración y explotación minera en glaciares y ambiente periglacial (Art. 6).

El mencionado inventario demoró ocho años en publicarse, al tiempo que la Ley no expresaba impedimentos para la realización de actividades prohibidas en áreas potencialmente protegidas hasta tanto se finalice el mismo (La protección de glaciares ya es ley, 2010) ${ }^{18}$ La metodología para su elaboración fue cuestionada por grupos ambientalistas, de modo que se incluyeron sólo los glaciares de extensión mayor a 
una hectárea, mientras que la normativa fija un relevamiento de todos los glaciares en tamaño y forma. ${ }^{19} \mathrm{El}$ Gobierno nacional fue acusado de obstaculizar el avance del inventario en glaciares de menos de una hectárea, porque un inventario completo pondría en jaque inversiones en 44 emprendimientos mineros. En cuanto a los resultados en la Provincia de Catamarca, se georreferenciaron 691 glaciares distribuidos en $64,88 \mathrm{~km} 2,{ }^{20}$ ninguno de ellos superpuesto espacialmente con el área de extracción de Minera Alumbrera Ltd. ${ }^{21}$

La Ley de Glaciares planteó una arena de disputa entre intereses particulares, gobiernos subnacionales y las necesidades de un país de preservar sus bienes comunes; tensada al extremo en el caso del emprendimiento Veladero, que opera en un área potencialmente protegida por la Ley de Glaciares en la Provincia de San Juan. Respecto de este caso, en junio del 2019 la Corte Suprema de Justicia desestimó el pedido de inconstitucionalidad de la Ley de Glaciares iniciado por la transnacional Barrick Gold Corporation en el año 2011. ${ }^{22}$ También en junio del 2019 -días después del mencionado fallo judicial-, el Gobierno de Catamarca inició acciones tendientes a debatir y definir los alcances de la Ley de Glaciares en la Provincia. Se trata de una incipiente iniciativa paradójicamente coordinada por la Secretaría de Estado de Minería -dependencia abocada a la promoción minera en la provincia-, que convocó a una primera reunión a empresarios, gremialistas, legisladores, proveedores y técnicos con el objeto de elaborar un proyecto a ser tratado en la Legislatura local. ${ }^{23}$ La Secretaria de Ambiente fue una voz ausente de esta tardía iniciativa, indicando formalmente una subordinación de la política ambiental a la actividad minera en Catamarca.

La actitud prominera de los gobiernos provinciales ha sido una constante, Minera Alumbrera Ltd. ha trasvasado partidos y alianzas políticas. En trabajo de campo, el Coordinador de Gabinete del Ministerio de Producción de Catamarca manifestó una presunta dependencia de la Provincia para con la actividad minera, en tanto señaló:

creo que Catamarca es una provincia minera y que necesita de la minería para poder seguir (...). Tenemos una Catamarca rica, me entiende, y no una Catamarca pobrecita como nos quieren vender (...). Una minería controlada es muy buena. (Coordinador de Gabinete del Ministerio de Producción del Gobierno de Catamarca, comunicación personal, 04 de diciembre de 2015).

Respecto al control estatal efectivo sobre la actividad, el mismo entrevistado señaló que hasta el año 2011 14 años luego de iniciada la extracción - la minería "era un tabú, (...) Catamarca estuvo años haciendo minería y realmente no sabía cuál era el impacto de la minería (...). Las gestiones anteriores eran muy light (...)”. ${ }^{24}$

En relación a las atribuciones y deberes de los municipios, la Constitución catamarqueña indica que estos deben preservar el sistema ecológico, los recursos naturales y el medio ambiente con la finalidad de garantizar las condiciones de vida de sus habitantes (Art. 252). En cuanto a las capacidades reales de los gobiernos locales para emprender dicha tarea, en el Municipio más próximo a Minera Alumbrera Ltd., Hualfín, se relevó que los recursos de la Dirección de Medio Ambiente, ubicada bajo la Secretaria de Obras Públicas, son extremadamente escasos. ${ }^{25}$ El Secretario de Producción ${ }^{26}$ expresó que en el municipio no hay personal especializado en el tema ambiental y que el gobierno local no tiene la capacidad de evaluar los impactos de la minera.

\section{CONSIDERACIONES FINALES}

En base al desarrollo presentado, a continuación, conceptualizaremos el rol del Estado Nacional y de la Provincia de Catamarca respecto de la institucionalización de la cuestión ambiental de cara a la inserción y avance de la minería a cielo abierto en el territorio catamarqueño.

En la legislación nacional y provincial, el ambiente resulta concebido de manera utilitaria, subyugado por la actividad económica y subordinado al modelo de desarrollo hegemónico. El ambiente resulta una dimensión 
escindida de los procesos decisorios sobre la definición del modelo de desarrollo, excepto como fuente de recursos naturales transferibles a la economía.

Lejos de gestionarse el ambiente desde un pensamiento holístico y multidimensional, su definición jurídico-normativa se inscribe en la racionabilidad económica occidental desde donde nace la ciencia moderna que divide la realidad en campos disciplinarios confinados. El Estado reconoce la contaminación y la degradación ecosistémica derivada del despliegue de la actividad económica, pero no plantea restricciones a la misma. Entonces, el horizonte político en materia ambiental es limitar y reparar los daños, no incidir en la planificación del desarrollo para promover determinados tipos de relaciones socioecológicas. En este sentido, la tajante subordinación del ambiente a la economía resulta inevitablemente acompañada de una infravaloración de actividades con relaciones socioecológicas menos contaminantes. ${ }^{27}$

En base al análisis realizado, se infiere que el rol del Estado Nacional y de la Provincia de Catamarca en la institucionalización ambiental se restringió al desarrollo de instrumentos normativos, legales y técnicos enfocados en evaluar y establecer relaciones aceptables (o no) del tipo costo-beneficio de la contaminación ambiental en función del desarrollo económico y social. En ese intento, daños ambientales resultan pasibles de ser traducidos en penalidades monetarias bajo el principio de responsabilidad. Por ello, se interpreta que los impactos ambientales negativos de la minería a cielo abierto se encaran de manera correctiva-defensiva. ${ }^{28}$

En el entramado normativo provincial, se ha visto nítidamente que la vocación minera de Catamarca se sobrepone al derecho ambiental de su población, de modo que la gestión ambiental se orientó a abastecer demandas del sector productivo minero considerando a la naturaleza como fuente de recursos físicos que pueden ser transferidos a la economía y, a la vez, resumidero de sus desechos. Por su lado, los gobiernos municipales, a pesar de constituirse en el nivel estatal más íntimamente ligado a los impactos ambientales de la actividad, los actores locales, su lugar de residencia y realización personal, resultan voces ausentes en la gestión y planificación ambiental relacionada con Minera Alumbrera Ltd.

El Estado Nacional acompañó la promoción e inserción de la minería a cielo abierto en el país con una legislación y un sistema de controles ambientales extremadamente laxos, con medidas de descentralización y fragmentación de las áreas encargadas de la aplicación de la Ley, sin fortalecimiento de las frágiles capacidades de gestión ambiental minera de niveles subnacionales. Al mismo tiempo, en materia económica, alentó la inversión en el sector con el ofrecimiento de seguridad jurídica y una serie de beneficios fiscales e impositivos asociados a un entramado de políticas que privilegiaron la inversión privada en la explotación intensiva de bienes comunes minerales.

La presunta dependencia de la Provincia de Catamarca respecto de la actividad minera, expresada en su legislación y en las entrevistas realizadas a funcionarios encargados de su aplicación, sumado a su rol de Estado anfitrión de una empresa transnacional especializada en la producción y comercialización de commodities a escala planetaria como Minera Alumbrera Ltd., da cuenta de una integración periférico-dependiente del territorio catamarqueño a la dinámica de la geografía económica globalizada con consecuencias en la pérdida de capacidad de la sociedad política local para disponer, conocer, controlar, organizar y administrar el propio territorio y, particularmente, sus bienes comunes naturales como es el caso extremo del agua.

Considerando el antecedente de los trabajos que demuestran los exiguos beneficios económicos que Minera Alumbrera Ltd. representa para las poblaciones próximas a la boca de mina, ${ }^{29}$ se entiende que la forma en que el Estado argentino - nacional y de la Provincia de Catamarca- articuló la institucionalización ambiental de la minería a cielo abierto implicó la socialización de sus costos ambientales -en las poblaciones locales- y la privatización de sus beneficios económicos -en los actores corporativos hegemónicos-.

\section{REFERENCIAS}

Adler, F. J. (2014). El futuro del agua en Tucumán. San Miguel de Tucumán: Yerba Buena. 
Alimonda, H., Pérez, C. T., y Martín, F. (Eds.). (2017). Ecología Política Latinoamericana. Pensamiento crítico, diferencia latinoamericana y rearticulación epistémica. Recuperado de http://biblioteca.clacso.edu.ar/clacso/gt/ 20171030111951/GT_Ecologia_politica_Tomo_I.pdf

Blanco, J. (2007). Espacio y territorio: elementos teórico-conceptuales implicados en el análisis geográfico. En M. Fernández Caso y R. Gurevich (coord.), Geografia. Nuevos temas, nuevas preguntas. Un temario para su enseñanza. Buenos Aires: Editorial Biblos.

Brailovsky, A. E. y Foguelman, D. (1991). Memoria Verde: Historia Ecológica de la Argentina. Buenos Aires: Editorial Sudamericana.

Bottaro, L. (2008). Nuevos movimientos socioterritoriales: Las asambleas de autoconvocados contra la minería metalifera a cielo abierto. En V Jornadas de Sociología de la UNLP. Facultad de Humanidades y Ciencias de la Educación de la Universidad de La Plata.

Bustamante, L. P. (2007). Los derechos de la sustentabilidad: desarrollo, consumo y ambiente. Buenos Aires: Ediciones Colihue SRL.

Catalano, E. (1999). Código de minería comentado. Buenos Aires: Zavalía.

Colby, M. (1991). La administración ambiental en el desarrollo: Evolución de los paradigmas. El Trimestre Económico, 58 (231), 589-615. doi: https://10.4135/9781412994064.n303

Delgado Ramos, G. C. (Ed.). (2010). Ecología política de la minería en América Latina: aspectos socioeconómicos, legales $y$ ambientales de la mega minería. México D. F.: Centro de Investigaciones Interdisciplinarias en Ciencias y Humanidades Universidad Nacional Autónoma de México. Recuperado de http://biblioteca.clacso.edu.ar/Me xico/ceiich-unam/20170502045538/pdf_1467.pdf

Delgado Ramos, G. C. (2014). Extractivismo, ecología política y la construcción de alternativas en América Latina. ALASRU. Nueva Época, 8, 17-45. Recuperado de http://www.alasru.org/pdf/REVISTA8/REVISTA8Alasru .Cap1.pdf

Falero A. (2013). El desarrollo de enclaves y la ilusión del desarrollo. Contrapunto, 2(2), 33-46. Recuperado de https ://dialnet.unirioja.es/servlet/articulo?codigo $=4350744$

Ferro, M. D. (2015). Paradigma ambiental e institucionalización juridica. Participación ciudadana y judicialización del conflicto por el saneamiento y recomposición ambiental de la Cuenca Matanza-Riachuelo (Tesis de doctorado en Derecho). Universidad de Buenos Aires, Buenos Aires, Argentina.

Godfrid, J. (2016). Mega-minería y colonialidad. Nuevas estrategias de legitimación, viejos binomios. Chasqui. Revista Latinoamericana de Comunicación, 131(31), 159-179. Recuperado de https://revistachasqui.org/index.php/ch asqui/article/view/2693

Gudynas, E. (2017). Extractivismos y corrupción en América del Sur. Estructuras, dinámicas y tendencias en una íntima relación. RevIISE - Revista de Ciencias Sociales y Humanas, 10(10), 73-87. Recuperado de http://www. ojs.unsj.edu.ar/index.php/reviise/article/view/197

Gutiérrez, R. A. y Isuani, F. (2013). Luces y sombras de la política ambiental argentina entre 1983 y 2013. Revista SAAP, 7(2), 317-328. Recuperado de http://www.scielo.org.ar/scielo.php?script=sci_arttext\&pid=S1853-197 02013000200010\&lng=es\&tlng=es.

Jiménez Herrero, L. M. (1997). Desarrollo sostenible y economía ecológica. Madrid: Editorial Síntesis.

La protección de glaciares ya es ley (30 de septiembre de 2010). Página 12. Recuperado de https://www.pagina12.co m.ar/diario/ultimas/20-154089-2010-09-30.html

Leff, E. (2003). La ecología política en América Latina. Un campo en construcción. Polis, Revista Latinoamericana, 2003 (5). Recuperado de https://journals.openedition.org/polis/6871

Leff, E. (2010). Ecología y Capital. Racionalidad ambiental, democracia participativa y desarrollo sustentable. México DF: Siglo XXI editores.

Machado Aráoz, H. (2009a). Auge minero y dominación neocolonial en América Latina. Ecología política de las transformaciones socioterritoriales neoliberales. XXVII Congreso de la Asociación Latinoamericana de Sociología. VIII Jornadas de Sociología de la Universidad de Buenos Aires. Asociación Latinoamericana de Sociología, Buenos Aires. Recuperado de http://cdsa.aacademica.org/000-062/1107 
Machado Aráoz, H. (2009b). Minería transnacional, conflictos socioterritoriales y nuevas dinámicas expropiatorias. El caso de Minera Alumbrera. En M. Svampa y A. Antonelli (eds.), Minería transnacional, narrativas del desarrollo y resistencias sociales (pp. 205-228). Buenos Aires: Biblios. Recuperado de https://exactasbienescomunes.files.w ordpress.com/2012/03/el-caso-de-minera-la-alumbrera-en-catamarca-machado.pdf

Machado Aráoz, H.; Svampa, M.; Viale, E.; Giraud, M.; Wagner, L.; Antonelli, M.; Giarracca, N.; Teubal, M. y Rodríguez Pardo, J. (2011). 15 mitos y realidades de la minería transnacional en Argentina: guia para desmontar el imaginario prominero. Buenos Aires: El Colectivo, Herramienta. Recuperado de http://biblioteca.clacso.edu .ar/Argentina/iigg-uba/20161025033400/15mitos.pdf

Machado Aráoz, H. (2015). Ecología política de los regímenes extractivistas. De reconfiguraciones imperiales y re-exsistencias decoloniales en nuestra América. Bajo el Volcán, 15(23). Recuperado de http://www.redalyc.org/res umen.oa?id=28643473002

Martínez Idrobo, J. P., y Figueroa Casas, A. (2014). Evolución de los conceptos y paradigmas que orientan la gestión ambiental ¿cuáles son sus limitaciones desde lo glocal?. Revista Ingenierías Universidad De Medellín, 13(24), 13-27. Recuperado de http://www.scielo.org.co/pdf/rium/v13n24/v13n24a02.pdf

Minera Alumbrera Ltd. (2017). Informe de sostenibilidad. Recuperado de http://www.alumbrera.com.ar/publicacion es/informes-de-sostenibilidad/

National Research Council (2008). Minerals, Critical Minerals, and the U.S. Economy. Washington, DC: The National Academies Press. https://doi.org/10.17226/12034.

Nieva, H. (2002). Variación de parámetros geoquímicos, rio Vis Vis, Catamarca, Argentina. Causas y consecuencias (Tesis de Maestría en Problemática Ambiental inédita). Instituto Politécnico de Lorraine, Escuela de Minas de NancyCentro de Estudios Superiores para el Tratamiento de Evoluciones y Mutaciones Industriales (CESTEMIN), Francia.

Perón, J. D. (1972). Mensaje Ambiental a los Pueblos y Gobiernos del Mundo. Recuperado de http://www.labaldrich.com.ar/wp-content/uploads/2013/03/Mensaje-Ambiental-de-Juan-Domingo-Per \%C3\%B3n-a-los-Pueblos-y-Gobiernos-del-Mundo-\%E2\%80\%93-Madrid-1972.pdf

Rodríguez Pardo, J. (2009). Vienen por el oro, vienen por todo: las invasiones mineras 500 años después. Buenos Aires: Ediciones CICCUS.

Rodríguez Pardo, J. (2011). Cronología de los delitos ambientales de La Alumbrera. En 15 mitos y realidades de la mineria transnacional en Argentina (pp. 114-116). Buenos Aires: El Colectivo, Herramienta.

Schweitzer, M.; Petrocelli, S; Scardino, M; Schweitzer, P; Arancio, M; Nerome, M y Carena, M. (2018). Estrategias, conflictos y tensiones en la producción del territorio. Estudios de caso sobre mineria, soja e hidrocarburos en Argentina. Buenos Aires: Autores de Argentina. Recuperado de http://isufaduuba.com.ar/?p=3396

Sola Álvarez, M. (2013). La disputa por la licencia social de los proyectos mineros en La Rioja, Argentina. Letras Verdes. Revista Latinoamericana de Estudios Socioambientales, 14, 27-47. https://doi.org/10.17141/letrasverdes.14.20 13.991

Svampa, M., Bottaro, L., y Sola Álvarez, M. (2009). La problemática de la minería metalífera a cielo abierto: modelo de desarrollo, territorio y discursos dominantes. En M. Svampa y A. Antonelli (eds.), Minería transnacional, narrativas del desarrollo y resistencias sociales (pp. 29-50). Recuperado de https://exactasbienescomunes.files.wo rdpress.com/2012/03/svampa-pag29-50.pdf

Svampa, M., y Viale, E. (2017). Continuidad y radicalización del neoextractivismo en la Argentina. Voces en el Fénix, 60. Recuperado de http://vocesenelfenix.com/content/continuidad-y-radicalizaci\%C3\%B3n-del-neoextractivi smo-en-la-argentina

Swyngedouw, E. (2011). ¡La naturaleza no existe! La sostenibilidad como síntoma de una planificación despolitizada. Urban, 01, 41-66. Recuperado de http://polired.upm.es/index.php/urban/article/view/410 


\section{Notas}

1 Si bien no es objeto de este artículo adentrarnos en el debate de este polisémico concepto, cabe decir que se entiende por desarrollo a una noción más amplia que la del crecimiento económico, incluye componentes sociales y se refiere a un cambio gradual dirigido al mejoramiento en la calidad de vida de las personas (Falero, 2013).

2 Entre 1990-1997 la explotación minera a nivel mundial creció el 90 \%, mientras que en América Latina lo hizo en un $400 \%$ (Bottaro, 2008).

3 Las estrategias de legitimación minera incluyen intervención social directa y otras de tipo comunicacionales (Godfrid, 2016). Se trata de un despliegue de acciones en múltiples escalas, no sólo en las localidades más afectadas durante el propio período de extracción, sino también a nivel nacional y a largo plazo.

4 Andalgalá en agosto de 2014, San Fernando del Valle de Catamarca, Belén y Hualfín en diciembre de 2015.

5 Directora de la Dirección Provincial de Gestión Ambiental Minera (DiPGAM), entrevistada en diciembre de 2015.

6 Funcionarios de la Secretaria de Obras Públicas del Municipio de Andalgalá, entrevistados en agosto del 2014.

7 Argentina fue uno de los países pioneros en ello. En 1973, Perón creó la Secretaria de Recursos Naturales y Ambiente Humano de la Nación para incorporar la perspectiva ambiental a la industria (Decreto 751/73), cuyos avances quedaron desactivados en 1976 con la política implementada por la última dictadura cívico militar.

8 Proliferaron las evaluaciones de impacto ambiental, realizadas sobre proyectos ya muy avanzados en su diseño.

9 Beneficios impositivos en impuesto a las ganancias, sobre los Activos y derechos a la importación de insumos y maquinarias, y la fijación del porcentaje máximo que las provincias pueden cobrar en concepto de regalías.

10 La problemática ambiental se encontraba instalada en la agenda internacional desde la Declaración de Estocolmo de 1972.

11 El ambiente, en sí mismo, no es sano ni deja de serlo, sólo podría ser adjetivado de esa forma desde un enfoque de subordinación al uso humano.

12 Entrevistado en su despacho en diciembre de 2015.

13 Fuentes: directora de la DIPGAM, entrevistada en diciembre de 2015, y http://noticiasmineras.com/legislacion-amb iental-mineria-argentina/

14 Secretario Académico y Subsecretaria de Gestión y Articulación Académica, entrevistados en diciembre de 2015.

15 Directora de la DiPGAM, entrevistada en diciembre de 2015.

16 Responsable del Centro de Control Minero Ambiental, entrevistada en diciembre del 2015.

17 El principio de sustentabilidad postula que "el desarrollo tanto económico como social y el aprovechamiento de los recursos naturales deben realizarse mediante una gestión apropiada del ambiente (...)" (Ley 25.675/2002).

18 https://www.pagina12.com.ar/diario/ultimas/20-154089-2010-09-30.html [consulta: 10 de septiembre de 2019]

19 http://www.unidiversidad.com.ar/ley-de-glaciares-una-norma-sin-aplicacion-plena77 [consulta: 12 de septiembre de 2019]

20 https://www.elesquiu.com/sociedad/2018/5/16/en-catamarca-hay-691-glaciares-segun-el-inventario-nacional-28591 5.html [consulta: 12 de septiembre de 2019]

21 En base a inventario de glaciares disponible en http://www.glaciaresargentinos.gob.ar/wp-content/uploads/resultados _finales/mapa_argentina_regiones_APN_11-05-2018.pdf [consulta: 12 de septiembre de 2019]

22 https://www.greenpeace.org/argentina/greenpeace/1720/ambientalistas-el-fallo-de-la-corte-marca-el-principio-del-fi n-para-la-mineria-sobre-glaciares/ [consulta: 12 de septiembre de 2019]; https://econojournal.com.ar/2019/07/barric k-invierte-us-34-millones-para-extender-la-vida-util-de-veladero/ [consulta: 16 de septiembre de 2019]

23 https://www.portal.catamarca.gob.ar/noticias/mineria-iniciara-el-trabajo-tecnico-por-la-ley-de-glaciares-5258/ [consulta: 16 de septiembre de 2019]

24 Coord. de Gabinete del Min. de Producción del Gob. de Catamarca, entrevistado en 2015.

25 Siendo su director un joven menor a 30 años con formación máxima de secundario completo y sin personal a cargo.

26 Entrevistado en diciembre de 2015.

27 Véase Paradigma de la Protección ambiental en Bustamante (2007) y Colby (1991).

28 Véase Paradigma de la Protección ambiental en Bustamante (2007) y Colby (1991).

29 Véase Schweitzer, Petrocelli, Scardino, Schweitzer, Arancio, Nerome, Carena (2018) 